\title{
Undernutrition and Associated Factors among Lactating Women: Community-Based Cross-Sectional Study in Moyale District, Borena Zone, Southern Ethiopia
}

\author{
Hailu Bekele, ${ }^{1}$ Gebi Husein Jima $\mathbb{D D}^{2}$ and Ashenafi Habtamu Regesu $\mathbb{D}^{2}$ \\ ${ }^{1}$ Public Health Expert at Moyale District, Oromia Regional State, Borana, Ethiopia \\ ${ }^{2}$ Department of Public Health, College of Health Science, Arsi University, Asella, Ethiopia \\ Correspondence should be addressed to Ashenafi Habtamu Regesu; imu.ashe@gmail.com
}

Received 9 April 2019; Accepted 25 March 2020; Published 22 April 2020

Academic Editor: Giuseppe La Torre

Copyright (C) 2020 Hailu Bekele et al. This is an open access article distributed under the Creative Commons Attribution License, which permits unrestricted use, distribution, and reproduction in any medium, provided the original work is properly cited.

Background. Undernutrition is one of the most widespread public health problems that affect both developed and developing countries. In Ethiopia, it is one of the factors leading to unacceptable high morbidity and mortality among women. However, little is documented on undernutrition among lactating women particularly in such a purely pastoral community. Therefore, this study was designed to assess prevalence of undernutrition and its associated factors among lactating women living in pastoral community of Moyale District, Borena Zone, Southern Ethiopia, 2018. Methods. A community-based cross-sectional study was conducted. Data were collected from a random sampled 545 lactating women using structured interviewer-administered questionnaire. Height and weight measurements of the study participants were also taken to compute body mass index. Data were entered in to Epi info version 7 and then exported to SPSS version 21 software for analysis. Descriptive statistics like frequency, mean, and percentage were computed to describe characteristics of the sample. Multivariable analysis was carried out, association between independent and dependent variables were measured using adjusted odds ratios, and its $95 \%$ confidence interval and $P$ value below 0.05 were considered statistically significant. Results. This study showed that prevalence of undernutrition among lactating women was $17.7 \%$. Dietary diversity $(\mathrm{AOR}=2.49,95 \% \mathrm{CI}: 1.43-4.36)$, monthly income (AOR $=5.22$, 95\% CI: $1.40-19.40)$, extra meal taking $(\mathrm{AOR}=2.76,95 \% \mathrm{CI}: 1.43-5.29$, delivery place ( $\mathrm{AOR}=2.65,95 \% \mathrm{CI}: 1.24-5.65)$, and household food insecurity $(\mathrm{AOR}=6.57,95 \% \mathrm{CI}$ : 3.50-12.34) were independent variables showing statistically significant association with undernutrition of lactating women. Conclusion and recommendations. The study revealed that magnitude of undernutrition among lactating women was high. Dietary diversity, monthly income, extra meal, delivery place, and household food insecurity were found to be predictor of undernutrition. Finally, we recommend that governmental and nongovernmental organizations should organize timely interventions targeting lactating women.

\section{Introduction}

Undernutrition refers to the outcome of insufficient food intake and/or poor absorption and/or poor biological use of nutrients consumed. It includes being underweight for one's age, too short for one's age (stunted), dangerously thin for one's height (wasted), and deficient in vitamins and minerals (micronutrient deficiencies) $[1,2]$. It takes place when the body doesn't receive the nutritional support it requires [3].

There are many contributing factors to undernutrition including poverty, poor hygiene, lack of nutritional knowledge, no access to water supplies, poor housing, access and utilization of health services, and cultural practices and discriminatory social structure which often occur together, and these create an environment of poor nutrition and susceptibility to infectious diseases [4], vulnerability of lactating women is high due to considerable elevation of nutrient requirements during lactation than in any other stage of a woman's reproductive life due to physiological change, and it imposes high metabolic demand on the women to nourish their children with breast milk of good concentration of important nutrients $[5,6]$. 
The energy cost of milk production in the first six months of exclusive breastfeeding increases women's daily energy needs by $30 \%$ or $1260 \mathrm{~kJ} /$ day above the pregnancy energy requirement, and this breast milk production has total energy value that requires average daily energy cost of breast feeding of approximately $2.9 \mathrm{MJ} /$ day [7].

The energy, protein, and other nutrients in breast milk come from the women's diet or from her own body stores. When women do not get enough energy and nutrients in their diets, repeated, closely spaced cycles of pregnancy and lactation can reduce their energy and nutrient reserves leading to a process known as maternal depletion [8]. This will lead to health effects in the women rather than the infant leading to potential health effects unless extra meal with good quality is made available to lactating women $[9,10]$.

Currently, 815 million people (11\% of global population) worldwide are living in hunger and are affected with all form of malnutrition due to different factors among which conflicts and climatic changes are the leading [11].

Globally, evidences show that about $13 \%$ of women are underweight and 33\% are anemic of which at least half because of iron deficiency and this number is higher in economically poor countries varying from by $20-25 \%$ for underweight and $48 \%-57 \%$ for anemia. Low body mass index $\left(<18.5 \mathrm{~kg} / \mathrm{m}^{2}\right)$ and/or short stature (height $<145 \mathrm{~cm}$ ) are common in women in low-income countries, with the highest rates in southern and southeastern Asia, followed by sub-Saharan Africa, with "critical" rates $(\geq 40 \%)$ in Eritrea $[12,13]$. Furthermore, in sub-Saharan Africa, data during 2000-2015 indicate that undernourishment prevails among 15-49 years of age in countries of the region ranging from lowest 3.2\% in Swaziland to 37.3\% in Eritrea where Ethiopia accounts $20 \%$ [14].

Undernutrition constrains the ability of women to fill their potential to the fullest. Hunger and undernourished women are not able to take on physical work, are less able to attend school, and also has consequence of economic loss. Africa and Asia lose 11\% of GDP every year due to poor nutrition while economic loss happens due to undernutrition [15]. In fact, it is not limited to only impacting the health and physical work capacity of the women but it is also one of reasons that put breast milk feeding children into the risk of inadequate feeding leading to stunting which is currently affecting about 155 million worldwide and 59 million in Africa [16].

In sub-Saharan Africa countries, there is a serious problem of maternal undernutrition caused by inadequate food intake, high energy expenditure, frequent reproductive cycle, and frequent infectious diseases like malaria and human immunodeficiency virus (HIV) resulting in unacceptably high morbidity and mortality rates as the region is highly exposed to natural and manmade disaster which led to socioeconomic problems [17, 18].

According to Ethiopia Nutrition Profile of 2014, household food insecurity, hunger, and undernutrition remain critical issues; the poor nutritional status of women and children has been a consistent problem in Ethiopia which causes about $27 \%$ of women of reproductive age to be undernourished, leaving their children predisposed to low birth weight, short stature, lower resistance to infections, and higher risk of disease and death [19]. In addition, according to Ethiopian Demographic and Health Survey 2016 (EDHS, 2016), 22\% of total women of reproductive age were undernourished based on their measure of BMI $\left(<18.5 \mathrm{~kg} / \mathrm{m}^{2}\right)$ and $8 \%$ were overweight/obese, and $29 \%$ pregnant and lactating women were anemic with hemoglobin level of less than $11 \mathrm{~g} / \mathrm{dl}$ [20].

The Government of Ethiopia has made a firm commitment to address food insecurity and undernutrition, by launching the National Nutrition Program (NNP) which was revised and relaunched by the government in 2013 and Health Sector Development Plan IV (2010-2015) and other initiatives to combat undernutrition $[19,20]$.

Finally, even though growing number of studies reported the existence of maternal undernutrition and different associated factors in different parts of the country, very few studies in Ethiopia highlighted the issue of undernutrition among the lactating women of the pastoral community of Ethiopia [14, 15, 17-20]. Most of studies did not include the nutritional knowledge of lactating women as a factor affecting the nutritional status of lactating women. Up to our knowledge, there is no study conducted on this subject in this particular area. The purpose of this study is, therefore, to assess the prevalence of undernutrition and associated factors among lactating women in Moyale District pastoral community, Borena, southern Ethiopia.

\section{Materials and Methods}

2.1. Study Design and Period. A community-based crosssectional study was employed to determine the prevalence and associated factors of undernutrition among lactating women from July 1 to July 30, 2018.

2.2. Setting and Participants. The study was carried out in the Oromia Regional State of Borena Zone, Moyale District. Moyale District is one of the 13 districts of Borena Zone, Oromia region, located at a distance of $775 \mathrm{~km}$ from Addis Ababa, the capital city of Ethiopia sharing international borders with Kenya to the south. Based on the 2007 Population and Housing Census projection, the total population is about 163,984 with a sex ratio of $1: 1$. All lactating women were considered as the source population, while selected (at least 6 months) lactating women in selected Kebeles were taken as study population during the study period.

2.3. Sample Size Determination. We estimated a sample size of 545 lactating women using single population proportion formula, assuming a $25.4 \%$ prevalence of malnutrition among lactating women from the study conducted in Samre, southeastern zone of Tigray, Ethiopia [21], with 0.05 margin of error with $95 \%$ confidence interval and using design effect of 2. Since the target population was $<10,000$, the finite correction formula was considered and $10 \%$ nonresponse rate was added to the total sample. 
2.4. Sampling Procedure. Fifteen Kebeles of Moyale District were clustered into 3 urbans and 12 rural kebeles, out of which 8 kebeles ( 2 urban and 6 rural) were selected by system random sampling with the lottery method, and the total sample size was proportionally allocated to each kebele. Using the Community Health Information System (CHIS) registration of households, lactating women were identified and sequential numbers were provided. The final study participants were identified using the systematic sampling method after the sampling interval in each kebele was determined by dividing the total number of households with lactating women by the allocated sample size. In case where more than one eligible respondent was found in the same selected household, only one respondent was chosen by the lottery method.

2.5. Data Collection. Data were collected through face-toface interview of lactating women in selected households using structured questionnaires adapted from the different literatures of similar studies $[22,23]$. The household food insecurity level was also measured with the Household Food Insecurity Access Scale (HFIAS), a tool which is validated in both urban and rural areas of Ethiopia to measure the household food security [24, 25].

The women's dietary intake pattern was measured by a qualitative recall of all foods consumed by each woman during the previous 24 hours, and thus certain food groups were aggregated to calculate individual (women's) dietary diversity score (IDDS/WDDS) [25].

Household monthly expenditure was indirectly measured by measuring the monthly household expenditure using the tool used by the FDRE Ministry of health to conduct household health service utilization and expenditure survey [26].

Nutritional knowledge of the women was assessed using the questionnaire containing 12 questions adapted from similar studies conducted previously [27, 28].

Anthropometric measurement (BMI) was taken from the study participants. For weight measurement, women were asked to remove their shoes and wear light cloths, and they were weighed on a calibrated portable digital scale and recorded the value to the nearest 0.1 kilogram. For height measurement, study participants were asked to stand erect with their shoulders leveled, hands at their sides, thighs and heels comfortably together, and the buttocks, scapulae, and head positioned in contact with the vertical backboard with a sliding head bar. Then, height values were recorded to the nearest $0.1 \mathrm{~cm}$. Body mass index (BMI) of the study subjects was calculated.

Four data collectors and two supervisors who were not working in the actual study area were recruited for the data collection, and two days' training was provided to data collectors and supervisors. A pretest was conducted before the actual data collection in similar setting out of the selected kebeles, and intensive supervision was made by principal investigator and supervisors.

2.6. Data Management and Analysis. Quantitative data were entered and cleaned using Epi Info version 7.2.2 and exported to SPSS version 21.0 for analysis. Descriptive statistics of the collected data like frequency, percentage, mean, and standard deviation were done for most variables in the study using statistical measurements.

The Women Dietary Diversity Score (WDDS) was calculated, and the mean score was used to classify the adequacy of women nutrient intake [29].

The Household Food Insecurity Access Scale (HFIAS) measured the household food security, and then the households were categorized into four categories as secured, mildly insecured, moderately insecured, and severely food insecured households and then recoded to dichotomize into secured and unsecured [30]. The outcome variable was recoded to dichotomous outcomes: either they are undernourished or not. Lactating women with $\mathrm{BMI}<18.5 \mathrm{~kg} / \mathrm{m}^{2}$ will be coded as " 1 " and those with BMI $\geq 18.5 \mathrm{~kg} / \mathrm{m}^{2}$ was coded "0." Mid-upper arm circumference (MUAC) of the women was measured, and $21 \mathrm{~cm}$ MUAC value was used as the cutoff point. The independent bivariate logistic regression model was used to assess the possible association between predictors and outcome variables.

All covariates that are significant at $P$ value $<0.2$ in bivariate analysis was considered for further multivariate analysis to control for all possible confounders and to detect true predictors of undernutrition. Multivariate logistic regression was fitted by using the enter method technique to identify determinants of undernutrition. The odds ratio along with $95 \%$ confidence interval was used to assess the association between the outcome variable and independent variables using multivariable logistic regression. Adjusted odds ratio along with $95 \%$ confidence interval was used to declare the statistically significant variables at $P<0.05$.

\section{Results}

3.1. Sociodemographic and Economic Characteristics of Lactating Women. A total of 532 lactating women aged 15-49 years participated, and the response rate was $97.6 \%$. More than half of respondents, 316 (59.4\%), were in the age group of $15-25$, and the mean \pm SD age was $25.8 \pm 5.4$ years. Concerning their residence, $346(65 \%)$ of the respondents were from rural area. Majority 432 (81.2\%) of the respondents were followers of the Muslim religion. Regarding their ethnicity, $382(71.7 \%)$ of study participants were Oromo. Concerning marital status, 504 (94.7\%) of the women were married and currently living with their husbands. Of the total study participants, 299 (56.2\%) cannot read and write. One-hundred fifty (28\%) of the study participants were pastoralist, and 207 (38.9\%) of them were unemployed. About 283 (53.2\%) of the households had a family size greater than 4 (Table 1).

3.2. Household Food Security Status. This study depicted that half of the study participants, 269 (50.6\%), worried about their food despite 229 (43.0\%) having no food type preference. In addition, this survey indicated that $139(26.1 \%)$ of the lactating women consumed unwanted food and 99 (18.6) also experienced limited food amount. Results from this survey showed that $63(11.8 \%)$ and $24(4.5 \%)$ of the study participants experienced limited amount of food and meal 
TABLE 1: Socioeconomic and demographic characteristics of lactating women $(N=532)$ in Moyale District, Borana, Southern Ethiopia, 2018.

\begin{tabular}{|c|c|c|c|}
\hline Variables & Categories & Frequency & Percent (\%) \\
\hline \multirow{3}{*}{ Age } & $15-25$ & 316 & 59.4 \\
\hline & $26-35$ & 192 & 36.1 \\
\hline & $36-49$ & 24 & 4.5 \\
\hline \multirow{2}{*}{ Residence } & Urban & 186 & 35.0 \\
\hline & Rural & 346 & 65.0 \\
\hline \multirow{4}{*}{ Religion } & Orthodox & 56 & 10.5 \\
\hline & Protestant & 26 & 4.9 \\
\hline & Muslim & 432 & 81.2 \\
\hline & Wakefata & 18 & 3.4 \\
\hline \multirow{4}{*}{ Marital status } & Married & 504 & 94.7 \\
\hline & Single & 1 & .2 \\
\hline & Divorced & 16 & 3.0 \\
\hline & Widowed & 11 & 2.1 \\
\hline \multirow{4}{*}{ Educational level } & Illiterate & 299 & 56.2 \\
\hline & Primary & 167 & 31.4 \\
\hline & High school & 42 & 7.9 \\
\hline & Diploma and above & 24 & 4.5 \\
\hline \multirow{4}{*}{ Educational status of husband } & Illiterate & 241 & 45.3 \\
\hline & Primary & 158 & 29.7 \\
\hline & High school & 86 & 16.2 \\
\hline & Diploma & 47 & 8.8 \\
\hline \multirow{5}{*}{ Occupation } & Pastoralist & 150 & 28.2 \\
\hline & Governmental & 23 & 4.3 \\
\hline & Private business & 54 & 10.2 \\
\hline & Trade & 98 & 18.4 \\
\hline & Jobless & 207 & 38.9 \\
\hline \multirow{5}{*}{ Occupation of husband } & Pastoralist & 163 & 30.6 \\
\hline & Governmental & 70 & 13.2 \\
\hline & Private business & 137 & 25.8 \\
\hline & Trade & 128 & 24.1 \\
\hline & Jobless & 34 & 6.4 \\
\hline \multirow{4}{*}{ Family monthly income } & $<1500$ & 55 & 10.3 \\
\hline & $1500-3000$ & 263 & 49.4 \\
\hline & $3000-4500$ & 164 & 30.8 \\
\hline & $>4500$ & 50 & 9.4 \\
\hline \multirow{2}{*}{ Household food security level } & Secured & 284 & 53.4 \\
\hline & Insecured & 248 & 46.6 \\
\hline \multirow{3}{*}{ Family size } & $\leq 4$ & 249 & 46.8 \\
\hline & $5-7$ & 209 & 39.3 \\
\hline & $>7$ & 74 & 13.9 \\
\hline
\end{tabular}

frequency, respectively. Table 2 summarizes the household food insecurity among lactating women in Moyale District.

Food insecurity level of households was assessed, and 277 (52\%) the households were food secured, while 138 (25.9\%), $94(17.7 \%)$, and $36(6.8 \%)$ fell into the category of mildly, moderately, and severely food-insecured households, respectively (Figure 1).

3.3. Health Care Utilization, Feeding Practice, and Environmental Characteristics of Lactating Women. With regards to family planning utilization, only $193(36.3 \%)$ of the total respondents had a history of family planning method utilization before pregnancy of the current child. Four-hundred and one (75.4\%) women got pregnant at the age below 19 years. Four-hundred ninety-five (93\%) women had ANC follow up during pregnancy of the current child, of which only $324(60.9 \%)$ had attended the fourth visit. Four- hundred and twelve (77.4\%)) of the study participants gave birth to the current child at the health institution. From the total women participated in this study, 376 (70.5\%) responded that they had received postnatal care from skilled health professionals at the time they gave birth to the current child. Of the total women included in this study, 436 (44.4\%) of them were breastfeeding children aged less than 6 months.

The mean dietary diversity score of lactating women was $4.6 \pm 1.6,296(55.6 \%)$ of the respondents had a dietary diversity score of $\geq 4.6$, while the rest $236(44.4 \%)$ had a dietary diversity score less than mean 4.6 . With regard to feeding practice of the respondents, 331 (62.2\%) of them had not used additional/extra meal during the lactation period of the current child.

Concerning toilet availability and utilization, 441 $(82.9 \%)$ of the household had own toilet, of which 343 $(64.5 \%)$ were able to use it properly. With regards to respondents' source of drinking water, 166 (31.2\%) were using 
TABLE 2: Household food insecurity assesses scale questions and response of lactating women $(N=532)$ in Moyale District, Borana, Southern Ethiopia, 2018.

\begin{tabular}{|c|c|c|c|c|c|c|}
\hline \multirow{2}{*}{ Question of occurrence } & \multirow{2}{*}{$\begin{array}{c}\text { Yes } \\
N(\%)\end{array}$} & \multirow{2}{*}{$\begin{array}{c}\text { No } \\
N(\%)\end{array}$} & \multicolumn{4}{|c|}{ Frequency of occurrence $N(\%)$} \\
\hline & & & 0 & 1 & 2 & 3 \\
\hline Worry about food & $269(50.6)$ & $263(49.4)$ & $263(49.4)$ & $105(19.7)$ & $68(12.8)$ & $96(18.1)$ \\
\hline No preference of food type & $229(43.0)$ & $306(57.5)$ & $306(57.5)$ & $93(17.4)$ & $70(13.2)$ & $66(12.4)$ \\
\hline Limit food type & $178(33.5)$ & $354(66.5)$ & $354(66.5)$ & $88(16.5)$ & $60(11.3)$ & $30(5.6)$ \\
\hline Feeding unwanted food & $139(26.1)$ & $393(73.9)$ & $393(73.9)$ & $71(13.3)$ & $49(9.2)$ & $19(3.6)$ \\
\hline Limit food amount & $99(18.6)$ & $433(81.4)$ & $433(81.4)$ & $58(10.9)$ & $28(5.3)$ & $13(2.4)$ \\
\hline Limit meal frequency & $63(11.8)$ & $469(88.2)$ & $469(88.2)$ & $31(5.8)$ & $25(4.7)$ & $7(1.3)$ \\
\hline No food in the house & $24(4.5)$ & $508(95.5)$ & $508(95.5)$ & $18(3.4)$ & $6(1.1)$ & 0 \\
\hline Hanger at night & $11(2.1)$ & $521(97.9)$ & $521(97.9)$ & $7(1.3)$ & $3(0.6)$ & $1(0.2)$ \\
\hline Hanger at day and night & $7(1.3)$ & $525(98.7)$ & $525(98.7)$ & $6(1.1)$ & $1(0.2)$ & 0 \\
\hline
\end{tabular}

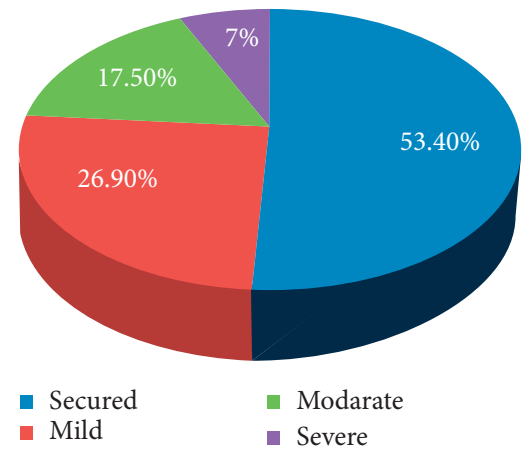

Figure 1: Household food security level of lactating women $(N=532)$ in Moyale District, Borana, Southern Ethiopia, 2018.

from unimproved sources (from unprotected source). Table 3 summarizes healthcare utilization, feeding practices, and environmental characteristics of lactating women.

3.4. Nutritional Knowledge Score of Lactating Women. With regards to knowledge of the lactating women, a proportion of below $34 \%, 34 \%-66 \%$, and above $67 \%$ was determined as poor, medium, and good nutritional knowledge, respectively [30]. Accordingly, 342 (64.2\%), 157 $(29.5 \%)$, and $33(6.2 \%)$ of lactating women who participated in the study were found to have poor, medium, and good nutritional knowledge, respectively (Table 4).

3.5. Nutritional Status of Lactating Women. Of the total lactating women participated in the study, $94(17.7 \%), 362$ $(68 \%)$, and $112(21 \%)$ of them were underweight $(<18.5 \mathrm{~kg} /$ $\left.\mathrm{ht}^{2}\right)$, have normal body weight $\left(\mathrm{BMI}=18.5\right.$ to $\left.24.99 \mathrm{~kg} / \mathrm{ht} \mathrm{t}^{2}\right)$, and overweight $\left(\mathrm{BMI}>25 \mathrm{~kg} / \mathrm{ht}^{2}\right)$, respectively. Hence, magnitude of BMI-based undernutrition among lactating women in the study area was $17 \%(\mathrm{BMI}=17.7 \%, 95 \% \mathrm{CI}$ : 14.2-20.9). Based on MUAC as a measurement of nutritional status, $16 \%$ of lactating women had undernutrition with MUAC less than $21 \mathrm{~cm}$ (MUAC $=16 \%, 95 \%$ CI: 13.1, 19.4) (Figure 2).

3.6. Level of Malnutrition among Lactating Women. On bivariate analysis the covariates, age of women, educational status of women, educational status of corresponding husband, feeding additional/extra meal, place of residence, dietary diversity score (DDS), household food insecurity of the women, household monthly income, age of the current child, delivery place, postnatal care, and water source for the household were associated with undernutrition among lactating women at a $P$ value below 0.2 . However, in multiple logistic regression, use of additional/extra meal, delivery place, family monthly income, dietary diversity score, and household food insecurity level were the variables that showed statistically significant association with undernutrition among lactating women. Accordingly, lactating women who did not take extra/additional meal during their lactation period were 2.66 times more likely to have undernutrition compared with their counterparts $(\mathrm{AOR}=2.66$, 95\% CI: 1.43-5.29).

Lactating women who have gave delivery at home for the current child were 2.65 times more likely to have undernutrition compared with who gave delivery at their home $(\mathrm{AOR}=2.66,95 \% \mathrm{CI}: 1.24-5.65)$. On the other hand, lactating women whose household monthly income was less than 1500 Ethiopian birr were 5.22 times more likely to have undernutrition compared with those who had greater than 4500 Ethiopian birr monthly income $(\mathrm{AOR}=5.222,95 \% \mathrm{CI}$ : $1.40-19.40)$.

In addition, lactating women whose household dietary diversity was less than the mean score were 2.49 times more likely to have undernutrition compared with those who had greater than or equal to mean score dietary diversity $(\mathrm{AOR}=2.495,95 \% \mathrm{CI}: 1.43-4.36)$.

Finally, lactating women who were from food insecured household were 6.57 times more likely to have undernutrition compared with their counterpart (AOR $=6.57,95 \%$ CI: 3.50-12.34. Table 5 shows the factors associated with malnutrition among lactating women.

\section{Discussion}

Women are generally vulnerable to undernutrition during lactation where the food and nutrient requirements are more during that period $[20,21,31,32]$. Thus, this study identified the overall prevalence of undernutrition and associated factors in the study area among lactating women. Accordingly, the prevalence of undernutrition among lactating women in Moyale District was $17.7 \%$. This 
TABLE 3: Maternal healthcare and feeding practice of lactating women $(N=532)$ in Moyale District, Borana, Southern Ethiopia, 2018.

\begin{tabular}{|c|c|c|c|}
\hline Variables & Category & Frequency & Percent (\%) \\
\hline \multirow{2}{*}{ ANC } & No & 37 & 7 \\
\hline & Yes & 495 & 93 \\
\hline \multirow{4}{*}{ Parity } & $\leq 2$ & 252 & 47.4 \\
\hline & $2-4$ & 152 & 28.6 \\
\hline & $5-6$ & 84 & 16.4 \\
\hline & $>6$ & 41 & 7.7 \\
\hline \multirow{3}{*}{ Family planning utilization } & No & 339 & 63.7 \\
\hline & Yes & 193 & 36.3 \\
\hline & First child & 106 & 19.9 \\
\hline \multirow[t]{2}{*}{ Birth interval } & $<2$ & 158 & 29.7 \\
\hline & $\geq 2$ & 268 & 50.4 \\
\hline \multirow{3}{*}{ Delivery place } & Health institution & 412 & 77.4 \\
\hline & Home & 120 & 22.6 \\
\hline & $<6$ & 236 & 44.4 \\
\hline \multirow{3}{*}{ Age of child } & $6-12$ & 183 & 34.4 \\
\hline & $>12$ & 113 & 21.2 \\
\hline & Total & 532 & 99.6 \\
\hline \multirow{2}{*}{ Dietary diversity score } & $\geq 4.6$ & 296 & 55.6 \\
\hline & $<4.6$ & 236 & 44.4 \\
\hline \multirow{2}{*}{ Diarrheal history of respondents } & No & 505 & 94.9 \\
\hline & Yes & 27 & 5.1 \\
\hline \multirow{2}{*}{ Toilette availability } & No & 91 & 17.1 \\
\hline & Yes & 441 & 82.9 \\
\hline \multirow{3}{*}{ Water source } & Unimproved & 166 & 31.2 \\
\hline & Improved & 366 & 68.8 \\
\hline & Total & 532 & 100.0 \\
\hline \multirow{2}{*}{ Proper toilet utilization } & No & 189 & 35.5 \\
\hline & Yes & 343 & 64.5 \\
\hline \multirow{2}{*}{ Frequency of ANC } & $\leq 3$ & 208 & 39.1 \\
\hline & $\geq 4$ & 324 & 60.9 \\
\hline \multirow{3}{*}{ Age at first pregnancy } & $<19$ & 401 & 75.4 \\
\hline & $>=19$ & 131 & 24.6 \\
\hline & $1-4$ & 249 & 46.8 \\
\hline \multirow[t]{2}{*}{ Family size } & $5-7$ & 209 & 39.3 \\
\hline & $>7$ & 74 & 13.9 \\
\hline \multirow{2}{*}{ Have nutritional information } & Yes & 328 & 61.7 \\
\hline & No & 204 & 38.3 \\
\hline \multirow{2}{*}{ Additional meal } & No & 331 & 62.2 \\
\hline & Yes & 201 & 37.8 \\
\hline
\end{tabular}

finding was similar to the prevalence of undernutrition among lactating women of the low land of Raya and Alamata Districts and community-based study conducted in Adama District reported as $17.5 \%$ and $19.5 \%$, respectively $[33,34]$ but lower than the study conducted in West Shao, Nekemte Referral Hospital and Womberma District of Northwest Ethiopia which were noted as $21.5 \%, 20 \%$, and $25.4 \%$, respectively [35-37]. This discrepancy might be due the attention given by the Federal Ministry of Health to maternal health and nutrition, engagement of NGO in the issues of nutrition in the study area and study design, and inclusion of both urban and rural settings in the current study population.

On the contrary, the result of this study was higher than the findings of studies conducted among lactating women in Offa woreda of Wolayita Zone and Indonesia which recorded $15.8 \%$ and $9 \%$, respectively $[38,39]$. This might be due to difference in the study areas and socioeconomic factor difference in Ethiopia and Indonesia.
MUAC was also used to assess the nutritional status of the lactating women. Consequently, the prevalence of undernutrition obtained from this study was $16 \%$ (MUAC $<21 \mathrm{~cm}$ ). This was very similar with the finding of the study conducted in Vietnam on lactating women which revealed the prevalence of undernutrition to be 15\% [40] and slightly lower than result obtained from Rayitu District of Ethiopia (24\%) [41].

Food insecurity affects the intake of adequate quantity and quality of diet that in turn contributes to maternal undernutrition. This study identified the household food insecurity was a strong predictor of nutritional status of lactating women. Women who were from food-insecured household were about 6.57 times more likely to be undernourished than those from food-secured houses, and a significant association was observed between the household food security level and BMI of lactating women. But, a finding from a similar study conducted in Ambo District showed that there was no statistically significant association 
TABLe 4: Nutritional knowledge score of lactating women $(N=532)$ in Moyale District, Borana, Southern Ethiopia, 2018.

\begin{tabular}{|c|c|c|c|}
\hline \multirow{2}{*}{ Series of questions } & & \multicolumn{2}{|c|}{ Correctly answered } \\
\hline & & Yes $(N(\%))$ & No $(N(\%))$ \\
\hline \multirow[t]{2}{*}{ Have information on nutrition } & & $328(61.7)$ & $204(38.3)$ \\
\hline & Health facility & $109(20.6)$ & \\
\hline \multirow{3}{*}{ Source of information } & Health EW & $191(35.8)$ & \\
\hline & School & $22(4.1)$ & \\
\hline & Media & $6(1.1)$ & \\
\hline Listed main food staff & & $213(40)$ & $319(60)$ \\
\hline Know use of protein & & $86(16.2)$ & $446(83.8)$ \\
\hline Listed source of protein & & $55(10.3)$ & $477(89.7)$ \\
\hline Know use of carbohydrate & & $39(7.3)$ & $493(92.7)$ \\
\hline Know the source of carbohydrate & & $41(7.7)$ & $491(92.7)$ \\
\hline Listed some vitamins and mineral foods & & $75(14.1)$ & $457(85.9)$ \\
\hline Know use of vitamins and minerals & & $59(11.1)$ & $473(88.9)$ \\
\hline Know that lactating women need extra meal & & $440(82.7)$ & $92(17.3)$ \\
\hline Know frequency of extra meal needed during lactation & & $390(73.3)$ & $142(26.7)$ \\
\hline Have encouragement from family member to have additional meal & & $415(78)$ & $117(22)$ \\
\hline \multicolumn{4}{|l|}{ Nutritional knowledge score of respondents } \\
\hline $0-33 \%$ (poor) & & 342 & 64.2 \\
\hline 34-66 (medium) & & 157 & 29.5 \\
\hline $67-100 \%$ (good) & & 33 & 6.2 \\
\hline
\end{tabular}

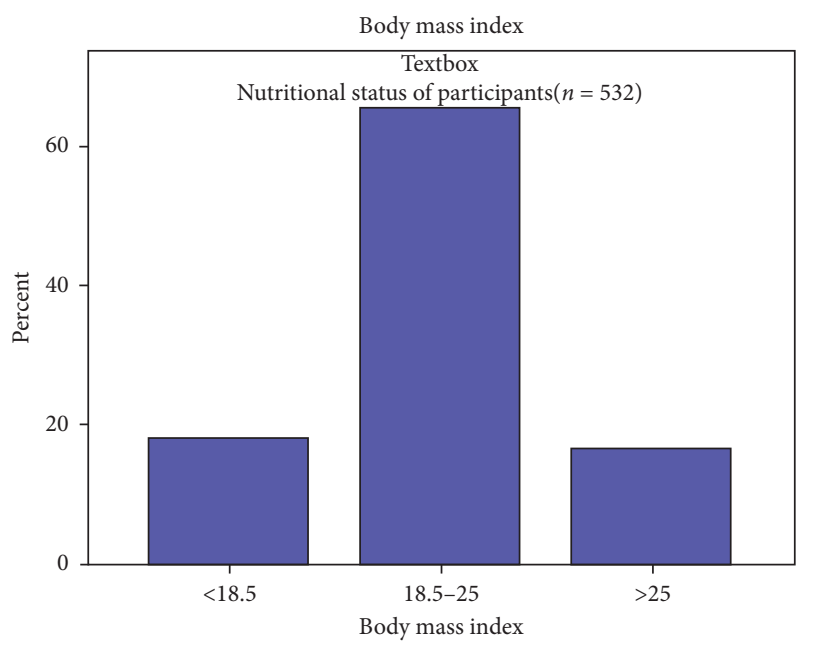

Figure 2: Nutritional status of lactating women $(N=532)$ using BMI in Moyale District, Borana, Southern Ethiopia, 2018.

between the household food security level and maternal undernutrition [35]. This discrepancy might be due to the presence of frequent drought in Moyale District which leads to food insecurity as compared with Ambo District.

During lactation, an additional meal/extra meal is recommended to ensure adequacy for lactating women. In the present study, extra meal consumption characteristic of lactating women was also significantly associated with undernutrition. Accordingly, lactating women who have not taken extra meal in addition to the usual meal she normally takes in house with family members were 2.66 times more prone to undernutrition than those who took extra meal during the lactation period. This finding was in agreement with the study conducted in the low land of Raya and Almata [33]. Furthermore, a systematic review made on maternal feeding practice and its outcome in developing countries also reported that undernutrition among women of reproductive age in developing countries including Ethiopia is due poor dietary intake below national or international recommendation [42].

Dietary diversity is a proxy indicator of maternal nutrient adequacy. Lactating women who had DDS less than mean DDS were about 3.49 times more likely to be undernourished than lactating women whose DDS was above mean DDS calculated in this study. This was supported by the finding obtained from the study conducted in Dedo and Seka Chekorsa Districts of Jima Zone of Ethiopia [22].

Maternal health service utilization characteristics of the women have consequences on health and nutritional statuses of women. In the current study, the delivery place of the women for the current child was found to be significantly associated with undernutrition. Lactating women who gave 


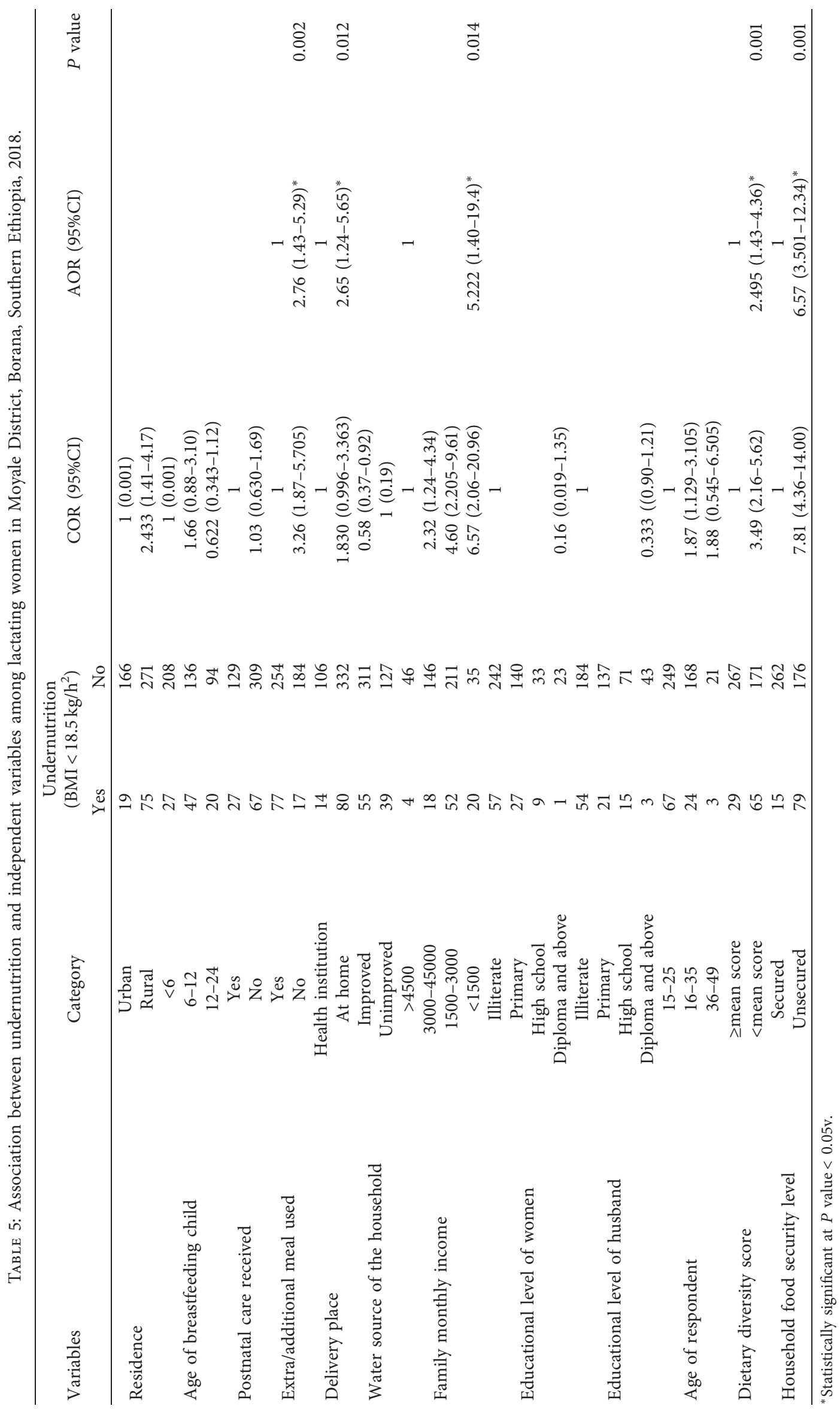


birth at home were 2.56 times more likely to be underweight when compared with women who deliver at a health institution. Other study conducted in Womberma District, northern Ethiopia, also reported that there was a significant association between the delivery place of women and their nutritional status [37].

\section{Conclusion}

Prevalence of undernutrition among lactating women was found to be a severe public health problem. Thus, this study depicted that the prevalence of undernutrition among lactating women in Moyale District of Borena Zone was 17.7\%. Use of additional/extra meal, delivery place, family monthly income, dietary diversity score, and household food insecurity level were important determinants factors of undernutrition among lactating women in the study area. In the meantime, we recommend Moyale District Health Office and Borena Zonal Health Department should enhance comprehensive health education and counseling of lactating women to improve their nutritional intake, institutional delivery, and dietary diversity during the lactating period. Furthermore, Zonal Agricultural Sector and Job Creation Department need to work on household food security and empower them for income-generating activities.

\section{Data Availability}

The data used to support the findings of this research are included within the article. The data can be obtained upon request from the corresponding author upon request (imu.ashe@gmail.com).

\section{Ethical Approval}

Ethical clearance was obtained from the Institutional Review Board (IRB) of Arsi University College of Health Sciences. The letter of permission to conduct the study was obtained from Borana Zone, Moyale District, and all selected kebeles. Before data collection, the participants were informed about the purpose of the study and their right to refuse participation and discontinue the interview/measurement. The interviewers discussed the issue of confidentiality and obtained the verbal consent from all selected women before the actual data collection. In addition, any identification information including the name of the participants was not written in the questionnaire. Undernourished infants and young children were linked to local nutritional programs in the area.

\section{Conflicts of Interest}

The authors declare that there are no conflicts of interest.

\section{Authors' Contributions}

Hailu Bekele Regassa involved in the proposal writing, designing, recruitment and training of supervisors and data collectors, and analysis and writeup of the paper. Gebi Husein Jima contributed to the conception and designing of the project proposal and methodology, led the study and design of questionnaires and supervised and involved in the analysis stage of the project, final approval of the research, and preparation of the manuscript. Ashenafi Habtamu Regesu contributed to the conception, designing of the project proposal, and methodology and involved in the analysis stage of the project and preparation of the manuscript. All the three authors read and approved the final manuscript.

\section{Acknowledgments}

We are very grateful to Arsi University College of Health Science and Oromia Regional Health Bureau for sponsoring the study. Our appreciation also goes to the Moyale District Health Office and Moyale District health team in the selected kebeles for their support during data collection. Our thanks also extend to all study participants for genuinely sharing the data cooperatively. Last but not the least, we are grateful to all data collectors and supervisors for their quality work and deliverance. The whole research fund was covered by Arsi University and Oromia Regional Health Bureau. However, the university and bureau had no role in the design of the study, collection, analysis, interpretation of data, and writing the manuscript.

\section{References}

[1] M. Blössner and M. de Onis, "Malnutrition: quantifying the health impact at national and local levels," in Environmental Burden of Disease Series, World Health Organization, Geneva, Switzerland, 2005.

[2] FSIN, Global Report on Food Crises 2018, Food Security Information Network, Rome, Italy, 2017.

[3] UN Global Nutrition Agenda, Delivering on the Commitment to Eradicate Malnutrition in All Its Forms: The Role of the UN System, UN Global Nutrition Agenda, New York, NY, USA, 2015.

[4] J. Fanzo, The Nutrition Challenge in Sub-Saharan Africa, United Nations Development Programme, Rome, Italy, 2012.

[5] J. Mann and A. S. Truswell, Essentials of Human Nutrition, United State: Oxford University Press, New York, NY, USA, 2002.

[6] Z. A. Bhutta, Maternal Malnutrition Globally: Epidemiology and Links to Childhood Malnutrition, SickKids Center for Global Child Health, Toronto, Canada, 2013.

[7] J. Mann, Essentials of Human Nutrition, J. Mann and A. S. Truswell, Eds., , Oxford University Press, New York, USA, 2nd edition, 2001.

[8] Linkages, "Effect of breastfeeding on maternal nutrition: breastfeeding and maternal nutrition frequently asked questions (FAQ)," 2004.

[9] C. Sherry and N. Pratt, Nutrition during Lactation: What Do Mom and Baby Need?, Abbott Nutrition Health Institute, Abbott Park, IL, USA, 2020.

[10] V. Quinn, A. Guyon, L. Martin, H. Neka-Tebeb, J. Martines, and C. SagoeMoses, "Nutrition and breastfeeding promotion," in Opportunities for Africa's Newborns, p. 104, World Health Organization, Geneva, Switzerland, 2006.

[11] WHO and FAO, The State of Food Security and Nutrition in the World, World Health Organization, Geneva, Switzerland, 2018. 
[12] USAID, Multi-Sectoral Nutrition Strategy Technical Guidance Brief, USAID, Washington, DC, USA, 2012.

[13] WHO, Nutrition of Women in the Preconception Period, during Pregnancy and the Breastfeeding Period, WHO, Geneva, Switzerland, 2012.

[14] WHO, Nutrition in the WHO African Region, WHO, Brazzaville, Congo, 2017.

[15] Institute IFPR, Global Nutrition Report 2014: Actions and Accountability to Accelerate the World's Progress on Nutrition, Institute IFPR, Washington, DC, USA, 2014.

[16] FAO, UNICEF, WFP, and WHO, "The state of food security and nutrition in the world 2017," FAO, Rome, Italy, 2017.

[17] A. Lartey, "Maternal and child nutrition in Sub-Saharan Africa: challenges and interventions," Proceedings of the Nutrition Society, vol. 67, no. 1, pp. 105-108, 2008.

[18] K. L. Lindsay, E. R. Gibney, and F. M. McAuliffe, "Maternal nutrition among women from Sub-Saharan Africa, with a focus on Nigeria, and potential implications for pregnancy outcomes among immigrant populations in developed countries," Journal of Human Nutrition and Dietetics, vol. 25, no. 6, pp. 534-546, 2012.

[19] USAID, Ethiopia: Nutrition Profile, USAID, Washington, DC, USA, 2014.

[20] CSA (Ethiopia), Ethiopia Demographic and Health Survey 2016: Addis Ababa, Ethiopia and Rockville, Maryland, USA: CSA and ICF, CSA, Addis Ababa, Ethiopia, 2016.

[21] K. M. A. Haileslassie and M. Girma, "Feeding practices, nutritional status and associated factors of lactating women in Samre Woreda, South Eastern Zone of Tigray, Ethiopia," Nutrition Journal, vol. 12, no. 1, 2013.

[22] M. Alemayehu, A. Argaw, and A. G. Mariam, "Factors associated with malnutrition among lactating women in subsistence farming households from Dedo and Seqa-Chekorsa districts, Jimma zone," Developing Country Studies, vol. 5, pp. 114-122, 2015.

[23] H. F. Gemede and D. Keneie, "Nutritional status and associated factors among lactating mothers in nekemte referral hospital and health centers, Ethiopia," Food Science and Quality Management, vol. 35, pp. 2224-6088, 2015.

[24] S. H. Gebreyesus, T. Lunde, D. H. Mariam, T. Woldehanna, and B. Lindtjørn, "Is the adapted household food insecurity access scale (HFIAS) developed internationally to measure food insecurity valid in urban and rural households of Ethiopia?" BMC Nutrition, vol. 1, no. 1, 2015.

[25] FAO, Minimum Dietary Diversity for Women a Guide for Measurement, FAO, Rome, Italy, 2016.

[26] Federal Democratic Republic of Ethiopia Ministry of Health, Ethiopian Health Accounts Household Health Service Utilization and Expenditure Survey 2015/2016, Federal Democratic Republic of Ethiopia Ministry of Health, Addis Ababa, Ethiopia, 2017.

[27] D. T. Hundera, H. F. Gemede, and D. Wirtu, "Nutritional knowledge and determinant factors among lactating mothers in nekemte referral hospital and health," Food Science and Quality Management, vol. 38, 2015.

[28] S. K. Masuku and S. J. Lan, "Nutritional knowledge, attitude, and practices among pregnant and lactating women living with HIV in the Manzini region of Swaziland," Journal of Health, Population and Nutrition, vol. 31, no. 2, pp. 261-269, 2014.

[29] L. Sobotka, P. Soeters, R. Meier, and Y. Berner, Undernutrition-Simple and Stress Starvation, European Society for Clinical Nutrition and Metabolism, Paris, France, 2006.
[30] J. Coates, A. Swindale, and P. Bilinsky, "Household food insecurity access scale (HFIAS) for measurement of household food access:," in Food and Nutrition Technical Assistance Project A, for Educational Development, USAID, Washington, DC, USA, 2007.

[31] Y. F. Macías, Guidelines for Assessing Nutrition-Related Knowledge, Attitudes and Practices, Food and Agriculture Organization of the United Nations, Rome, Italy, 2014.

[32] A. N. Ongosi, Nutrient Intake and Nutrition Knowledge of Lactating Women (0-6 months Postpartum) in a Low SocioEconomic Area in Kenya, University of Pretoria, Pretoria, South Africa, 2010.

[33] K. S. Ismael, H. Kiday, and A. Yohannes, "Comparison of nutritional status and associated factors of lactating women between lowland and highland communities of District Raya, Alamata, Southern Tigiray, Ethiopia," BMC Nutrition, vol. 3, no. 1, 2017.

[34] K. M. Biru, A. Jima, and S. G. Abeya, "Prevalence of chronic energy malnutrition and maternal health service utilizations among lactating mothers in Adama district, Oromia region, eastern Ethiopia," Journal of Food Processing \& Technology, vol. 8, no. 1, 2017.

[35] E. Zerihun, G. Egata, and F. Mesfin, "Under nutrition and its associated factors among lactating mothers in rural Ambo district, west Shewa zone, Oromia region, Ethiopia," East African Journal of Health and Biomedical Sciences, vol. 1, no. 1, pp. 39-48, 2016.

[36] T. D. Hundera, H. F. Gemede, D. Wirtu, and D. N. Kenie, "Nutritional status and associated factors among lactating mothers in nekemte referral hospital and health centers, Ethiopia," Food Science and Quality Management, vol. 35, 2015.

[37] S. Berihun, G. M. Kassa, and M. Teshome, "Factors associated with underweight among lactating women in Womberma woreda, Northwest Ethiopia; a cross-sectional study," BMC Nutrition, vol. 3, no. 1, 2017.

[38] B. W. Julla, A. Haile, G. Ayana, S. Eshetu, D. Kuche, and T. Asefa, "Chronic energy deficiency and associated factors among lactating mothers (15-49 years old) in Offa Woreda, Wolayita zone, SNNPRs, Ethiopio," World Scientific Research, vol. 5, no. 1, pp. 13-23, 2018.

[39] S. Madanijah, R. Rimbawan, D. Briawan et al., "Nutritional status of lactating women in Bogor district, Indonesia: crosssectional dietary intake in three economic quintiles and comparison with pre-pregnant women," British Journal of Nutrition, vol. 116, no. S1, pp. S67-S74, 2016.

[40] M. Nakamori, N. X. Ninh, H. Isomura et al., "Nutritional status of lactating mothers and their breast milk concentration of iron, zinc and copper in rural Vietnam," Journal of $\mathrm{Nu}$ tritional Science and Vitaminology, vol. 55, no. 4, pp. 338-345, 2009.

[41] B. Gebre, S. Biadgilign, Z. Taddese, T. Legesse, and M. Letebo, "Determinants of malnutrition among pregnant and lactating women under humanitarian setting in Ethiopia," $\mathrm{BMC} \mathrm{Nu-}$ trition, vol. 4, no. 1, 2018.

[42] Z. Tafese and A. Kebebu, "A systematic review of maternal feeding practice and its outcome in developing countries," Journal of Nursing Women's Healthcare, vol. 2, no. 4, 2017. 